\title{
Impulsivity makes more susceptible to overeating after contextual appetitive conditioning
}

Citation for published version (APA):

van den Akker, K., Jansen, A., Frentz, F., \& Havermans, R. C. (2013). Impulsivity makes more susceptible to overeating after contextual appetitive conditioning. Appetite, 70, 73-80.

https://doi.org/10.1016/j.appet.2013.06.092

Document status and date:

Published: 01/11/2013

DOI:

10.1016/j.appet.2013.06.092

Document Version:

Publisher's PDF, also known as Version of record

Document license:

Taverne

Please check the document version of this publication:

- A submitted manuscript is the version of the article upon submission and before peer-review. There can be important differences between the submitted version and the official published version of record.

People interested in the research are advised to contact the author for the final version of the publication, or visit the DOI to the publisher's website.

- The final author version and the galley proof are versions of the publication after peer review.

- The final published version features the final layout of the paper including the volume, issue and page numbers.

Link to publication

\footnotetext{
General rights rights.

- You may freely distribute the URL identifying the publication in the public portal. please follow below link for the End User Agreement:

www.umlib.nl/taverne-license

Take down policy

If you believe that this document breaches copyright please contact us at:

repository@maastrichtuniversity.nl

providing details and we will investigate your claim.
}

Copyright and moral rights for the publications made accessible in the public portal are retained by the authors and/or other copyright owners and it is a condition of accessing publications that users recognise and abide by the legal requirements associated with these

- Users may download and print one copy of any publication from the public portal for the purpose of private study or research.

- You may not further distribute the material or use it for any profit-making activity or commercial gain

If the publication is distributed under the terms of Article $25 \mathrm{fa}$ of the Dutch Copyright Act, indicated by the "Taverne" license above, 
Research report

\title{
Impulsivity makes more susceptible to overeating after contextual appetitive conditioning ${ }^{\text {in }}$
}

\author{
Karolien van den Akker*, Anita Jansen, Florentine Frentz, Remco C. Havermans \\ Faculty of Psychology and Neuroscience, Department of Clinical Psychological Science, Maastricht University, P.O. Box 616, 6200 MD Maastricht, The Netherlands
}

\section{A R T I C L E I N F O}

Article history:

Received 21 March 2013

Received in revised form 18 June 2013

Accepted 22 June 2013

Available online 4 July 2013

\section{Keywords:}

Appetitive conditioning

Impulsivity

Cue reactivity

Salivation

Overeating

\begin{abstract}
A B S T R A C T
Animals can learn that specific contexts are associated with important biological events such as food intake through classical conditioning. Very few studies suggest this is also possible in humans and contextual appetitive conditioning might even be a main determinant of habitual overeating in vulnerable humans. A Virtual Reality laboratory was used to test whether humans show conditioned responding (increased food desires and expectations, increased salivation and increased food intake) to a specific context after repeated pairings of this context with intake. It was also examined whether the personality trait impulsivity strengthens this contextual appetitive conditioning. Conditioned context-induced reactivity was indeed demonstrated and impulsivity predicted increased intake in only the intake-associated context. It is concluded that humans easily learn desires to eat in intake-related environments. The data also suggest that in particular more impulsive people are vulnerable for conditioned context-induced overeating. This relatively easy learning of associations between specific contexts and intake might stimulate habitual overeating and contribute to increased obesity prevalence.
\end{abstract}

(c) 2013 Elsevier Ltd. All rights reserved.

\section{Introduction}

The prevalence of overweight and obesity has been rapidly increasing, adversely affecting quality of life and leading to increased health care costs (Flegal, Carroll, Ogden, \& Curtin, 2010; Sturm, 2002). The obesogenic environment plays an important role in the current rise in obesity prevalence (Swinburn, Egger, \& Raza, 1999), although it is not clear yet why some people are more vulnerable to overeat in a tempting environment than others. The abundant environment is characterized by many cues that signal high-calorie food availability (Burton, Smit, \& Lightowler, 2007; Rodin \& Slochower, 1976), and classical conditioning has been put forward as a mechanism that might explain why it is so difficult for some people to resist environmental temptations: in case of strong reinforcers, like tasty high-calorie foods, one easily learns to associate a predictor of intake with the actual eating. The learning of such an association facilitates cue-elicited eating: the cue prepares the person for intake, for instance by increasing salivation, elicits a desire to eat, and stimulates actual eating, frequently in the absence of physical hunger (Jansen, 1998; Jansen,

\footnotetext{
Acknowledgements: The authors would like to thank Jacco Ronner and Lotty Huijboom for excellent technical assistance in developing the Virtual Reality program for this study. Conflict of interest: The authors declare no conflict of interest.

* Corresponding author.

E-mail address: karolien.vandenakker@maastrichtuniversity.nl (K. van den Akker).
}

Stegerman, Roefs, Nederkoorn, \& Havermans, 2010; Wardle, 1990). Virtually any cue has the ability to become associated with food intake and to elicit preparatory responses of the body. These preparatory responses, also termed cephalic phase responses, are thought to be experienced as a desire to eat (Jansen, 1998; Nederkoorn, Smulders, \& Jansen, 2000; Powley, 1977). Both the physiological preparatory responses and eating desires are labeled cue reactivity (Jansen, 1998; Jansen et al., 2010). Classical conditioning studies with animals show that contexts might act as conditioned stimuli as well: sated rats showed an increased food intake in a cage previously associated with eating (Boggiano, Dorsey, Thomas, \& Murdaugh, 2009; Petrovich, Ross, Gallagher, \& Holland, 2007). The current obesogenic environment provides many opportunities to associate everyday contexts with food intake and therefore is able to elicit frequently recurring cue reactivity and overeating in conditioned contexts. Indeed, it has been found that among eating behavior characteristics the strongest correlate of future weight gain was habitual overeating, or the susceptibility to overeat in response to everyday cues within the environment (Hays \& Roberts, 2007).

Very few experimental studies have been conducted investigating classical conditioning as causal mechanism for context-induced cravings and overeating in humans. In these studies, an initially neutral contextual stimulus is repeatedly paired with food intake (the unconditioned stimulus, US) so this context becomes a predictor (conditioned stimulus, CS) for consumption. A study in preschool children found evidence of contextual conditioning of meal initiation (Birch, McPhee, Sullivan, \& Johnson, 1989), and 
a conditioning procedure using chocolate shows differential acquisition of craving and automatic approach tendencies towards a specific contextual cue (a tray) (Van Gucht, Baeyens, Hermans, \& Beckers, 2013; Van Gucht, Baeyens, Vansteenwegen, Hermans, \& Beckers, 2010; Van Gucht, Vansteenwegen, Beckers, \& Van den Bergh, 2008; Van Gucht, Vansteenwegen, Van den Bergh, \& Beckers, 2008).

Appetitive conditioning studies usually do not take personality characteristics into account. It is known however that obesity, overeating and impulsivity frequently go together; several studies have found that trait impulsivity is positively associated with obesity (Nederkoorn, Braet, Van Eijs, Tanghe, \& Jansen, 2006; Nederkoorn, Smulders, Havermans, Roefs, \& Jansen, 2006; Rydén et al., 2003). Furthermore, impulsivity has been associated with increased food cue reactivity (Tetley, Brunstrom, \& Griffiths, 2010), increased attention for food cues (Hou et al., 2011), binge eating (De Zwaan et al., 1994; Nasser, Gluck, \& Geliebter, 2004) and increased food intake (Guerrieri, Nederkoorn, \& Jansen, 2008; Nederkoorn, Braet, et al., 2006). It has even been reported that obese children receiving cognitive behavior therapy lost significantly less weight with increasing impulsivity (Nederkoorn, Jansen, Mulkens, \& Jansen, 2007). A possible role of impulsivity in conditioning has been proposed as well. Gray's BIS-BAS theory postulated that trait impulsivity should be related to activation of a system sensitive to appetitive conditions (i.e., the behavioral activation system or BAS) (Corr, Pickering, \& Gray, 1995). It can be argued that impulsives' stronger output of the BAS is related to changes in arousal and emotional states which in turn can strengthen CS-US associations currently undergoing processing (Corr, 2001). Other authors have proposed impulsivity to be related to an increased strength (and/ or number) of appetitive associational resources, thereby rendering them predisposed to forming appetitive associations (Zinbarg \& Revelle, 1989). However, evidence for the validity of these models is scarce (e.g., Corr et al., 1995; Gupta \& Shukla, 1989; Paisey \& Mangan, 1988; Zinbarg \& Mohlman, 1998). Knowing that impulsivity is positively associated with overeating and obesity, it is of interest to study whether impulsivity predicts a facilitated acquisition of conditioned responding to a CS that signals a food reward and in this way stimulates overeating in especially the high impulsive people.

In the present study, a Virtual Reality (VR) laboratory is used to create different contexts that are either associated with milkshake intake or not. In VR, participants are immersed in a programmed three-dimensional world, while perceiving this virtual world as 'real' (Hoffman, Richards, Coda, Richards, \& Sharar, 2003). These complex environments likely have a stronger connection to reallife situations than the usual distinct stimuli (e.g., pictures or objects). It is expected that after conditioning, the intake-associated environment (CS+) will elicit a stronger desire for milkshake, an increased expectancy to receive milkshake, more salivation and an increased intake during a bogus taste test, compared with a control environment ( $\mathrm{CS}-$ ). The $\mathrm{CS}+$ is also expected to be liked more. Further, it is predicted that impulsivity facilitates conditioning.

\section{Methods and materials}

\section{Participants}

Seventy participants took part in the study. Female students were invited for participation if they were proficient in Dutch, aged between 18 and 25 years, had a normal BMI (19-25) and were in the 1 st or 2 nd year of their bachelor program. Furthermore, to be included in the study their score on the Restraint Scale had to be below 15, meaning that they are unrestrained eaters (Polivy, Herman, \& Howard, 1988), and a requisite was that they liked at least one milkshake flavor (vanilla, chocolate, or strawberry). The questions were incorporated into a set of filler items. Participants were asked to have a small meal (e.g., a sandwich) two hours prior to the experiment, and to refrain from calorie intake thereafter. To reduce demand characteristics, participants were told that this study was about investigating the influence of environmental stimulation on taste perception'. They received either $€ 10$ or were given course credits for participation. The study's procedure was approved by the local ethical committee.

\section{Measures}

\section{Questionnaires were administered in Dutch}

Desire and expectancy: $100 \mathrm{~mm}$-Visual Analogue Scales (VAS) were used to assess subjective desire for milkshake and expectancy to receive milkshake (Huskisson, 1974; Van Gucht, Vansteenwegen, Van den Bergh, et al., 2008). The desire-VAS was accompanied by the question 'How strong is your desire for milkshake at this moment?', and the expectancy-VAS was accompanied by the question 'How strong do you expect to be allowed to taste milkshake at this moment?'. Ratings ranged from 0 (no desire for milkshake at all) certainly expect not to taste milkshake) to 100 (very strong desire for milkshake/certainly expect to taste milkshake). The order of presentation of these two VASs was randomized.

Salivation: Salivation was measured using dental rolls (Hartmann, $\mathrm{nr} 2,10 \times 35 \mathrm{~mm}$ ) which the participant was instructed to place and remove herself. Two dental rolls were placed between the cheek and lower gum on the left and right side. A third, halved dental roll was placed under the tongue. They were removed after precisely one minute. The dental rolls were kept in a sealed plastic bag and their weight was registered before and after the saliva was collected, using a weighing scale accurate to $0.01 \mathrm{~g}$ (Mettler Toledo, PB3002).

Intake during taste test: Ad libitum milkshake intake was measured during a 5-min bogus taste test, during which participants answered questions about supposed differences between three identical milkshakes. The flavor of these milkshakes was identical to the flavor during conditioning (vanilla, chocolate, or strawberry). Liking of the milkshake was measured during the taste test. The milkshakes were weighed before and after the taste test to assess total food intake. Each cup contained approximately $250 \mathrm{~g}$ of milkshake, equivalent to $300 \mathrm{ml}$ and $450 \mathrm{kcal}$.

CS preference: CS liking was measured using two different questionnaires. Before and after conditioning, participants rated their liking for the CS+ and CS - environments on a VAS accompanied by the question 'How much do you like this environment?', ranging from 0 (not at all) to 100 (very much). Additionally, after conditioning, participants were asked to give a ranking on how much they liked the four different virtual environments they had been exposed to, from most liked to least liked. This was done to assess the preferred $\mathrm{CS}(\mathrm{CS}+$ or $\mathrm{CS}-$ ).

Contingency awareness: Participants completed a contingency awareness check to find out whether they were aware of the association between the CS+ and milkshake intake.

Presence: Feelings of presence in the virtual environments were measured using a questionnaire, adapted from another study (Hoffman, Hollander, Schroder, Rousseau, \& Furness, 1998; experiment 2, items A, D, E G). An average score was calculated. This was assessed since low levels of presence can have a substantial impact on responding (Witmer \& Singer, 1998).

Nausea: To check for nausea due to exposure to virtual environments, participants were asked to indicate whether they felt nauseated before and after AR exposure on a VAS ranging from 0 (not at all nauseated) to 100 (extremely nauseated).

Hunger: To control for hunger at the start of the experiment, participants filled in a VAS accompanied by the question 'How hungry are you at this moment?' ranging from 0 (not hungry at all) to 100 (extremely hungry). 
Milkshake liking: To control for possible differences in liking of milkshake, participants filled in a VAS accompanied by the question 'How much did you like the milkshakes?' ranging from 0 (not at all) to 100 (extremely).

Barrett Impulsivity Scale-11 (BIS-11; Patton, Stanford, \& Barratt, 1995): The BIS-11 was used to measure impulsivity. It is a self-report questionnaire and consists of 30 items. Each statement can be rated on a 4-point scale, ranging from rarely/never to always/almost always. Total scores were calculated, a higher score indicating higher impulsiveness. The BIS-11 has good internal consistency and good construct validity (Patton et al., 1995).

Revised Restraint Scale (RS; Polivy et al., 1988): The 10-item RS was used to assess dietary restraint, i.e. the intention to restrict food intake. Scores range from 0 to 35 , a higher score indicates increased intentions to restrain intake.

Stimuli

US

The intake of milkshake served as the US. During conditioning, small milkshake cups with lid and a translucent straw were used. Each cup was weighed before and after a conditioning trial. One cup contained approximately $10 \mathrm{~g}$ (18 kcal) of freshly-prepared milkshake, of which on average $5.41 \mathrm{~g}( \pm 1.22)$ was ingested during a CS+ trial. The milkshakes were kept in a cooler that remained out of sight of the participants at all times. Milkshakes could not be smelled.

CS

Four different virtual environments were used. One environment served as practice and acclimation environment, which was a largely empty room. The other three environments were presented during conditioning: An Italian square served as the (neutral) environment that appeared during the inter-trial interval (ITI), and two rooms served as CS+ or CS-; one of these depicted (non-food related) paintings, a window and seats, another room depicted a dojo (Japanese room to practice martial arts). These environments were accompanied by two distinct musical pieces (Beethoven's Violin romance No. 2 F major and Mussorgsky's Pictures at an Exhibition), which have been found to be emotionally neutral (Mitterschiffthaler, Fu, Dalton, Andrew, \& Williams, 2007). Which room and musical piece combination (four combinations) served as CS+ or CS- was counterbalanced across participants.

\section{Augmented Reality (AR)}

In AR, virtual environments are visible, but objects that are close to the participant in the real world can still be perceived (Botella et al., 2005). In this experiment, AR was used so the participant could see her own hands and the milkshakes, and she was able to fill out VAS questionnaires. To display the virtual environments, a Head-Mounted Display (HMD) was used (NVIS nVisor ST50), which was placed on the head of the participant. An HMD enables the display of virtual environments on screens inside the HMD. A tracking system was used to precisely locate movements of participants' heads (PhaseSpace), and the images projected on the screens inside the HMD change according to the participants' movements. Thus, when a participant turns her head to the left, the virtual images change according to her head movement. The software used for programming is Vizard Virtual Reality Toolkit, WorldViz. A sound system was used to play pre-recorded instructions and musical pieces (Ambisonic Auralizer System, WorldViz).

\section{Design and procedure}

See Fig. 1 for an overview of the study's design. Participants were run individually between $11 \mathrm{AM}$ and $6 \mathrm{PM}$. Upon arrival in the laboratory, the participant gave written consent. She was seated at a table during the whole experiment. The participant was instructed on how to fill in a VAS, and was then asked to rate her hunger and nausea. Also, a baseline measure of saliva production was conducted. When looking around in the virtual

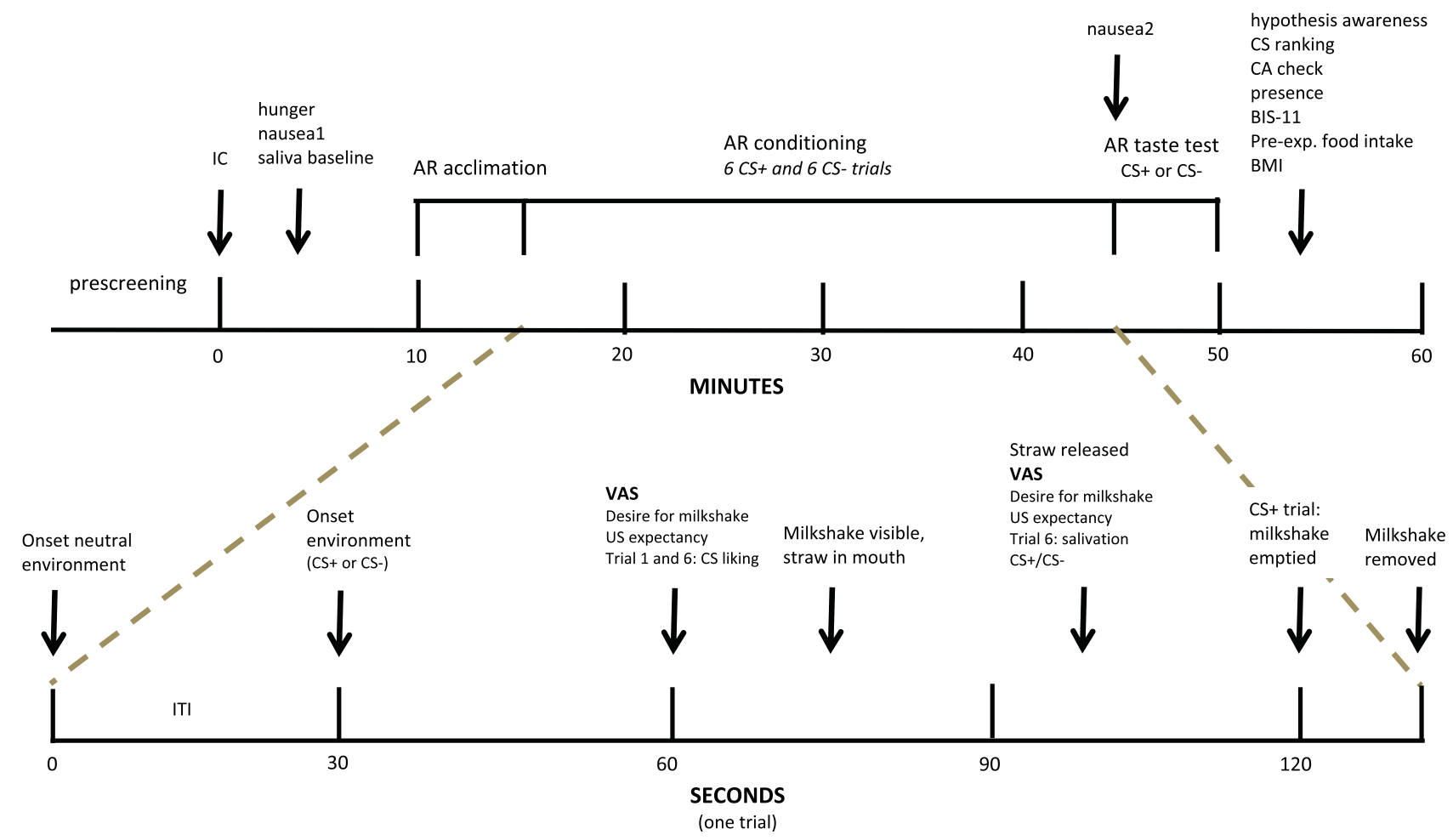

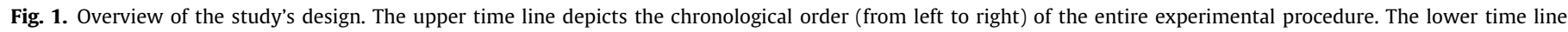
specifies a single conditioning trial. The onset of an environment automatically causes the offset of the previous environment. 
environment, she had to take care not to move her head too fast, which was done to minimize cybersickness. She was explicitly informed that one of the environments would be followed by being asked to drink something. After thirty participants had participated in the study, twelve still appeared unaware of an association between the rooms and being allowed to drink milkshake. Therefore, we changed the instructions regarding the CS-US contingency slightly by additionally showing participants colored, printed pictures of the environments during this introduction session (no milkshake was given yet).

A participant first received an acclimation and practice session in AR, after which the conditioning procedure started (duration approximately $30 \mathrm{~min}$, see Fig. 1). She then performed a taste test in either the CS+ or CS- environment, depending on which condition she had been assigned to. Assignment to a condition was random and counterbalanced. All instructions given during conditioning and the taste test were pre-recorded and played through the sound system.

\section{Conditioning}

In total, $6 \mathrm{CS}+$ and $6 \mathrm{CS}$ - trials were presented to each participant. The order of the presentation of these trials was random, but with the restriction of no more than two consecutive trials of the same trial type. Further, the first two and last two trials always consisted of one CS+ and one CS-, counterbalanced across participants.

A trial started when the CS+ or CS- environment became visible. The participant was told to look around slowly. After $30 \mathrm{~s}$, she filled out the first desire and expectancy-VAS. Then, a milkshake cup was placed on the table in front of her, and she picked it up and placed the milkshake's straw into her mouth but was not allowed to drink. She still was exposed to the environment. After another $30 \mathrm{~s}$, she placed the cup on the table and filled in the second desire and expectancy-VAS. In case of a CS - trial, the milkshake cup was now removed. In case of a CS+trial, the participant picked up the milkshake cup again and emptied it. After this, the inter-trial interval (ITI) started, during which the neutral environment appeared for $30 \mathrm{~s}$. During the $1 \mathrm{st}$ and 6 th CS+ and CS - trials, CS liking was assessed. On both the 6th CS+ and the 6th CS - trial, salivation was measured. After all conditioning trials had been completed, the participant filled in a 2 nd nausea VAS during the ITI, after which the taste test started.

\section{Taste test}

Depending on the participant's assigned environment, the CS+ or CS- environment was presented during the taste test. Three large milkshake cups with lids were placed in front of the participant. The participant received questions about the taste of the milkshakes, and was told that if she would finish early she was invited to drink as much as she liked to. After the taste test the HMD was removed.

\section{Questionnaires}

After the taste test, the participant filled out the following questionnaires: her ideas about the study's hypotheses, CS ranking, contingency awareness, presence, BIS-11, and time of pre-experimental food intake. Finally, the participant's weight and height were measured. She was thanked for participation and received her reward.

\section{Results}

\section{Exclusion of participants and statistical analyses}

Three participants were excluded from analysis: one participant because she felt too nauseated to perform the taste test,
Table 1

Participant characteristics across conditions, means with standard deviations in parentheses.

\begin{tabular}{lllll}
\hline & CS+ taste test & CS- taste test & $F(1,65)$ & $p$ \\
\hline$n$ & 34 & 33 & & \\
Contingency aware & 25 & 26 & & \\
Age & $19.71(1.53)$ & $19.67(1.83)$ & 0.01 & .92 \\
BMI & $22.06(2.08)$ & $21.49(1.72)$ & 1.51 & .22 \\
Baseline hunger & $48.74(21.33)$ & $49.45(24.10)$ & 0.02 & .90 \\
BIS-11 & $60.59(8.08)$ & $58.18(9.46)$ & 1.26 & .27 \\
Restraint Scale & $9.48(2.98)$ & $9.42(3.26)$ & 0.09 & .77 \\
Presence & $57.06(12.78)$ & $55.88(16.83)$ & 0.10 & .75 \\
Baseline milkshake liking & $65.88(24.55)$ & $73.85(14.80)$ & 2.57 & .11 \\
Nausea & $26.35(27.78)$ & $13.67(17.60)$ & 4.95 & .03 \\
\hline
\end{tabular}

a Due to missing data, the degrees of freedom for this analysis were 1,64 .

another because she did not understand the instructions and a third was excluded because she scored $>3$ SDs above the mean on the BIS-11.

Despite the explicit instructions regarding the US-environment association, a substantial part of the sample $(23.9 \%$; see Table 1 ) could not retrospectively indicate which room had been followed by being allowed to drink milkshake and/or did not develop a differential expectancy. These participants were classified as not being aware of the contingency between an environment and the opportunity to drink (non-CA). Previous studies have shown that contingency awareness is likely necessary for the formation of associations (Hogarth, Dickinson, Hutton, Bamborough, \& Duka, 2006; Lovibond \& Shanks, 2002). Therefore, contingency awareness was included as a between-subjects variable in the ANOVAs.

Differential acquisition of expectancy and desire for milkshake were analyzed using $2 \times 6$ (CS-type $\times$ Trial) repeated-measures ANOVAs. Analyses were conducted on the 2nd expectancy and desire-VAS scores of each trial. ${ }^{1}$ Saliva production was also analyzed using repeated-measures ANOVA, with measurement (baseline, $\mathrm{CS}+, \mathrm{CS}-$ ) as within-subjects variable, as was CS liking, with CS-type $\left(\mathrm{CS}+, \mathrm{CS}_{-}\right)$and Trial $(1 \mathrm{st}, 6 \mathrm{th})$ as within-subjects variables. Preference for the CS+ over the CS- was tested using a binomial test. The total score of the BIS-11 was included as covariate in the ANOVAs to study effects of impulsivity on US-expectancy, desire for milkshake, salivation and CS liking. A student's t-test was used to test for differences in milkshake consumption across conditions (taste test environment: $\mathrm{CS}+$ or $\mathrm{CS}-$ ). A hierarchical linear regression model was used to analyze the effects of impulsivity and condition on milkshake consumption. Greenhouse-Geisser epsilon corrections are reported for repeated-measures analyses whenever sphericity was violated.

\section{Participant characteristics}

No significant differences across conditions emerged for age, BMI, hunger, BIS-11 total, RS, presence and milkshake liking, however nausea differed significantly between conditions (see Table 1).

\section{US-expectancy and desire for milkshake}

Overall, differential acquisition of expectancy was present, as indicated by a significant CS-type $\times$ Trial interaction, $F(3.12,202.50)=33.84, p<.001$ (see Fig. 2a). Including contingency awareness (CA) as between-subjects variable yielded a significant CS-type $\times$ Trial $\times$ CA interaction, $F(3.62,231.62)=14.93, p<.001$. Contingency non-aware participants failed to develop differential

\footnotetext{
1 Each trial included two VAS measurements for each CS-type. Analyses including
} the first VAS scores of each trial revealed similar patterns. 

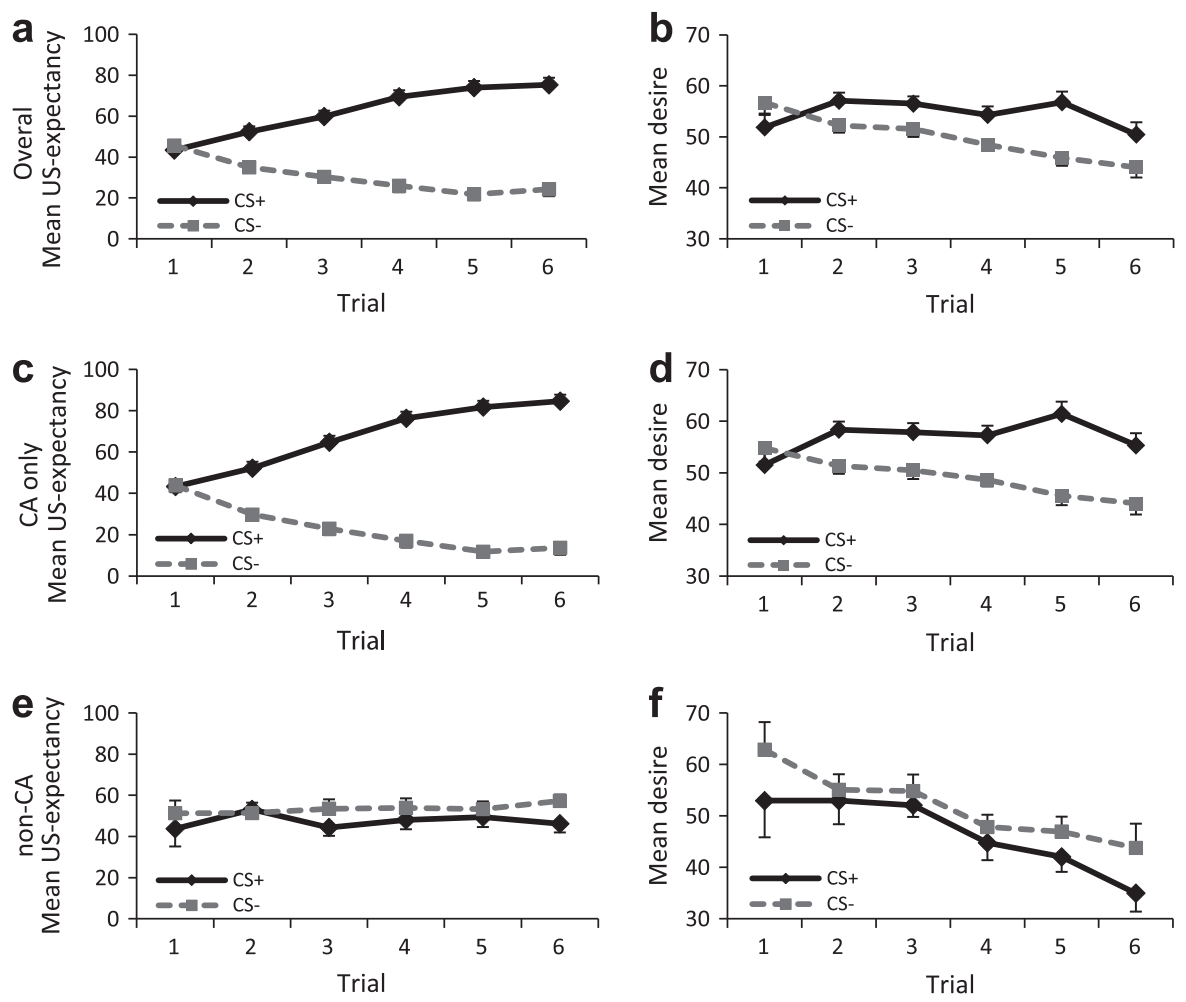

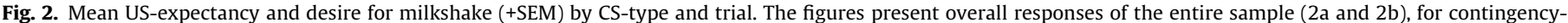
aware participants only ( $2 \mathrm{c}$ and $2 \mathrm{~d}$ ), and for non-contingency-aware participants only (2e and $2 \mathrm{f}$ ).

expectancy, $F(5,75)=0.46, p=.81$ (see Fig. $2 c$ and e). Impulsivity had no significant effect on the differentiation, $F(3.18$, 203.34) $=1.68, p=.17$.

Participants also developed a differential acquisition of the desire for milkshake, as shown by a significant CS-type $\times$ Trial interaction, $F(3.03,200.51)=5.81, \quad p=.001 \quad$ (see Fig. 2b). This differentiation was characterized by a decrease in desire for milkshake in response to the $C S-, F(2.98,196.43)=7.38, p<.001$, while no change in desire for milkshake was found for the CS+, $F(3.10,204.50)=1.90, p=.13$.

No significant interaction between acquisition of differential desire for milkshake and CA was found, $F(3.04,197.27)=1.39, p=.25$. However, the CA $\times$ trial interaction was significant, $F(3.04,197.27)=$ $2.67, p<.05$, indicating an overall decrease in desire for milkshake in the non-CA group, $F(2.69,39.35)=4.65, p=.001$ but no overall change in the CA group, $F(3.00,150.20)=1.09, p=.36$ (see Fig. $2 \mathrm{~d}$ and f). Impulsivity did not influence differential desire over time, $F(3.03,197.07)=0.68, p=.57){ }^{2}$

\section{Salivation}

Salivation differed significantly between the three measurements, $F(2,128)=4.97, p=.01$, with Bonferroni-corrected pairwise comparisons indicating that salivation in the CS+ was significantly higher than baseline $(p=.01)$ but not compared with salivation in the CS $-(p=.49)$. Salivation in the CS - did not significantly differ from baseline $(p=.32)$ (see Fig. 3). No interaction with CA was found, $F(2,126)=0.06, \quad p=.94$, nor with impulsivity,

\footnotetext{
2 The differential acquisition of US-expectancy and desire for milkshake did not differ between the conditions, as the CS-type $\times$ Trial $\times$ Condition interactions were not significant, $F(3.10,198.56)=0.85, p=.47 ; F(3.03,196.77)=1.13, p=.34$. Thus, as expected, the conditions did not differ in acquisition of differential US-expectancy and desire for milkshake.
}

$F(2,126)=0.42, p=.66$. As expected, the conditions did not differ in salivation pattern, $F(2,126)=1.71, p=.19$.

\section{Milkshake consumption}

\section{Overall}

Taste test environment did not influence total milkshake consumption, $t(65)=0.28, p=.78$ [mean consumed milkshake in the CS+: $137.23 \mathrm{~g}$ ( \pm 97.39$)$; CS-: $130.73( \pm 89.00)]$.

\section{Impulsivity}

To examine influences of impulsivity on milkshake consumption, a hierarchical regression analysis was conducted (see Table 2 and Fig. 4). Both nausea and milkshake liking correlated significantly with total milkshake consumption, $r(65)=-0.25, p=.04$, $r(65)=0.25, p<.05$ and with each other, $r(65)=0.42, p<.001$. Since the conditions significantly differed in nausea but not in liking (see Table 1: nausea in the CS+ condition was higher), nausea was included in the regression model. ${ }^{3}$ All variables were centered before entering in the regression model. The analysis showed that condition and impulsivity interacted $\left(\Delta R^{2}=0.06, p=.04\right)$. Followup analyses revealed that participants who were highly impulsive (1 SD above the mean of the BIS-11) consumed significantly more milkshake in the $\mathrm{CS}+$ than in the $\mathrm{CS}-(p=.04)$. In contrast, within low-impulsive participants ( 1 SD below the mean of the BIS-11) no difference in milkshake consumption between the conditions was found $(p=.44)$. Analyzing the slope of the CS- regression line revealed a trend $(p=.08)$, suggesting a decreased food intake in the

\footnotetext{
${ }^{3}$ When excluding participants who scored highest on nausea (scoring $\geqslant 50$ on the 2nd nausea-VAS, $n=10$ ) instead of entering nausea as covariate in regression analysis, the condition $*$ impulsivity interaction remained significant $\left(\Delta R^{2}=0.09, p=.03\right)$.
} Thus, both methods to control for nausea resulted in similar effects. 


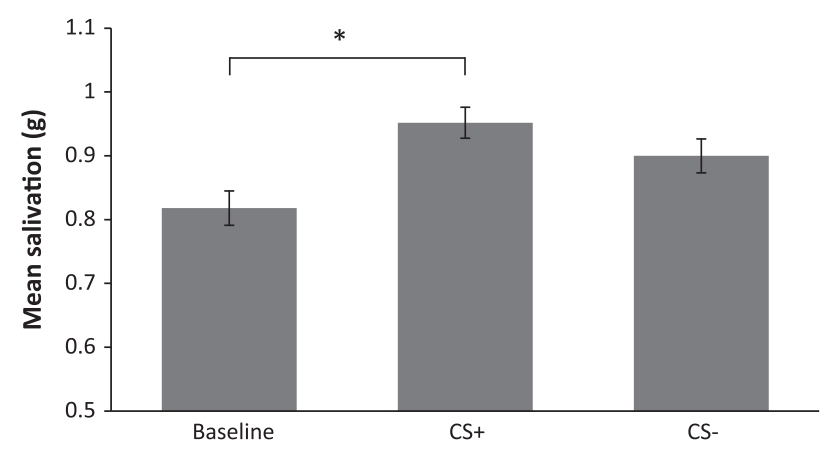

Fig. 3. Mean salivation (+SEM) at baseline, $\mathrm{CS}+$ and $\mathrm{CS}-$.

Table 2

Summary of the hierarchical regression analysis.

\begin{tabular}{llll}
\hline Variable & $B$ & $B$ (s.e.) & $\beta$ \\
\hline Step 1 & & & \\
Nausea & -0.98 & 0.47 & $-0.25^{*}$ \\
Step 2 & & & \\
Nausea & -1.11 & 0.49 & $-0.29^{*}$ \\
Condition & -22.09 & 23.47 & -0.12 \\
Impulsivity & -0.65 & 1.30 & -0.06 \\
Step 3 & & & \\
Nausea & -0.93 & 0.48 & $-0.24^{\#}$ \\
Condition & -18.97 & 22.92 & -0.10 \\
Impulsivity & 2.43 & 1.95 & 0.23 \\
Condition $\times$ impulsivity & -5.35 & 2.59 & $-0.38^{*}$ \\
\hline
\end{tabular}

$R^{2}=0.06$ for Step $1(p=.04), \Delta R^{2}=0.02$ for Step $2(\mathrm{~ns}), \Delta R^{2}=0.06$ for Step 3 $(p=.05)$.

$p<.05$.

\# $p<.06$.

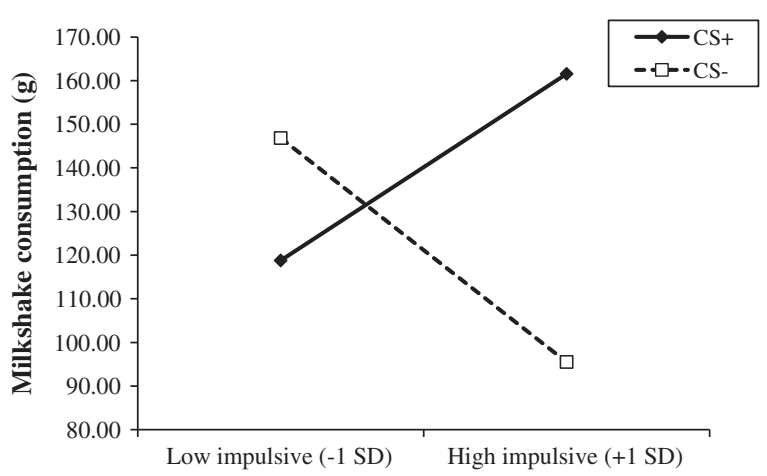

Fig. 4. Milkshake consumption in low and high impulsive participants, for the CS+ or CS - taste test.

$\mathrm{CS}$ - in more impulsive relative to less impulsive participants. The slope of the CS+ regression line was not significant $(p=.24)$.

\section{$C A$}

CA was added to the model (not shown in the model) and was not found to predict milkshake consumption overall, $\beta=-.09$, $t(62)=-0.72, p=.47$. Furthermore, no significant Condition $\times$ Impulsivity $\times$ CA interaction was found, $\beta=-.002, t(60)=-0.02$, $p=.99$, suggesting no differences in milkshake consumption patterns between CA and non-CA participants.

\section{CS liking}

Conditioned CS liking was evident with repeated-measures analyses when including CA in the CS-Type $*$ Trial interaction, $F(1,63)=5.92, p=.02$; CA participants developed a significant differentiation in CS liking, $F(1,49)=6.67, p=.01$ [mean change in CS+ liking: $0.80( \pm 14.84)$; $C S-:-8.10( \pm 18.48)$ ], whereas nonCA participants did not, $F(1,14)=1.79, p=.20$ [mean change in CS+ liking: -8.43 ( \pm 18.79$)$; CS-: $0.13( \pm 13.37)$ ]. Impulsivity did not have an effect on this interaction, $F(1,61)=2.21, p=.14$. In the ranking, the $\mathrm{CS}+$ was not more preferred than the $\mathrm{CS}-$; the CS+ was preferred by $56 \%$ of the participants, $p=.46$.

\section{Discussion}

This study provides evidence of contextual appetitive conditioning in females. After six conditioning trials, conditioned cue reactivity in response to the contextual CS+ was found: participants salivated significantly more in response to this context compared to baseline and this increase was non-significant for the CS-. Likewise, the contextual CS+ elicited a greater desire for milkshake and higher US expectations than the CS- after conditioning. Differential CS+ liking increased on the within-subjects assessment in contingency-aware participants, also indicating conditioned responding. In line with previous research, this conditioning appeared to depend largely on awareness of the contingency between the CSs and the US. Impulsivity did not moderate the acquired context cue reactivity (salivation and subjective responses). However, increased consumption after appetitive conditioning was found in impulsive participants: high impulsive participants consumed more milkshake when being present in the CS+ compared with the CS-, while low impulsive participants consumed similar amounts in the $\mathrm{CS}+$ and $\mathrm{CS}-$.

This study contributes to the existing literature by showing that not only isolated proximal food cues but also complex non-food related environmental stimuli are able to become triggers of conditioned appetitive responding in humans. Another new finding was that preparatory responses of the body (salivation) may be involved in human contextual appetitive conditioning: we found some evidence that initially neutral contexts are able to elicit an adaptive physiological change that is similar to physiological reactions to the sight or smell of food. The current obesogenic environment (context) offers many potential opportunities to associate different contexts (e.g., home, office, friends) with calorie intake, and in this way stimulates contextual appetitive conditioning. Contextual eating might be considered a form of habitual eating that occurs relatively automatic without people being aware of these conditioning processes and context-induced cue reactivity. Intriguingly, those participants in our sample who were unaware of the CS-US contingency also showed some evidence of conditioned responding on the behavioral measures, suggesting that they, too, prepared for food intake. Not intervening on these conditioning processes might make it more difficult to change overeating patterns. It was for instance found that conditioned food cue reactivity was absent in successful post-obese dieters - presumably extinguished - whereas it was present in unsuccessful obese dieters (Jansen, Havermans, \& Nederkoorn, 2011; Jansen et al., 2010).

Another new and intriguing finding is that impulsivity was a significant predictor of milkshake consumption in the CS+. Although the milkshake US was available in both the CS+ and $\mathrm{CS}$ - during the taste test (in large amounts), only the more impulsive participants ingested significantly more milkshake in the foodassociated environment (and not in the $\mathrm{CS}-$ ). Since impulsivity did not appear to moderate the acquisition of other conditioned responses over trials, these data seem to suggest that impulsivity as measured by the BIS-11 is not related to a facilitated acquisition whereas it is to the behavioral expression of the (conditioned) motivational state (i.e., increased intake) (Corr, 2001). This is consistent with previous research reporting that increased food intake in impulsive participants only occurs when participants are hungry 
(Nederkoorn, Guerrieri, Havermans, Roefs, \& Jansen, 2009). Our findings are also in line with the idea that 'rash impulsiveness' is related to an inability to inhibit predominant approach responses, since our present measure of impulsivity (the BIS-11) is supposed to provide a measure of this form of impulsiveness (Dawe, Gullo, \& Loxton, 2004). Thus, once an approach response was activated by the CS+, the high impulsives in our study might have been unable to inhibit approach behavior and subsequently increased their food intake. On the other hand, the present findings also suggest a trend towards higher impulsivity being related to a suppression of intake in the CS-, possibly pointing towards more effective response inhibition in a non-food associated context (see also Jansen, Klaver, Merckelbach, \& van den Hout, 1989). In the CS-, participants were exposed to milkshake cups but were not allowed to consume the milkshake. It is possible that the more impulsive participants had to put greater effort into inhibiting their approach response in the CS-, which could have led to effective inhibitory learning in impulsives in specifically this context. This suggests that high impulsives (e.g., binge eaters and people with obesity) could benefit from food cue exposure therapy, in which a food cue is repeatedly presented while the actual eating is prevented (i.e., inhibited) in order to decrease cue reactivity. However, the present experiment was not designed to test these ideas, and future studies should include truly neutral stimuli to see whether the increased intake in the CS+ compared with the CS- in higher impulsives is due to facilitatory or inhibitory mechanisms, or a combination of both.

It is possible that impulsivity is related to an increased speed of acquisition of conditioned responding to food cues under certain conditions. For instance, previous findings have suggested that both the size and type of the US may be important for an increased acquisition speed in impulsives: extraverts vs. introverts have been found to show stronger appetitive conditioning of electrodermal responses when stronger, but not when weaker, sexual stimuli were involved (Paisey \& Mangan, 1988), and a positive relation between reward responsiveness and speed of acquisition of US expectancies has been reported when a monetary reward was involved but not when an ego-related reward was involved (Zinbarg \& Mohlman, 1998). In contrast, in our study, participants received a food reward during conditioning which was relatively weak (i.e., a very small amount of milkshake). Additionally, the same reward may be perceived differently by different participants; for instance, impulsive individuals could have been disappointed by the small US in the present study (Corr, 2001). Moreover, different measures or forms of impulsivity might also be differentially related to appetitive conditioning (Corr, 2001; 'Papachristou, Nederkoorn, Beunen, \& Jansen, 2013).

Cue and context-elicited cravings are well-known in addiction research (Drummond, 2001). Cue exposure therapy has been used in the treatment of both addiction and eating disorders. A major problem with cue exposure treatment is renewal, in which a supposedly extinguished response re-emerges after treatment when a patient returns to the acquisition environment (Bouton, 2002; Havermans \& Jansen, 2003). This is thought to occur because of differences between the contexts in which the behavior was learned, extinguished and tested, and stresses the need for exposures in the context that is associated with intake or use (Bouton, 2002; Havermans \& Jansen, 2003; Jansen, 1998; Thewissen, Van Den Hout, Havermans, \& Jansen, 2005). VR and AR could therefore become useful tools for improving cue exposure therapy: it is possible to create contexts very similar to those in which one usually overeats or uses a drug. Researchers conducting experiments and/or therapies involving food in AR or VR should however be aware of the possibility of inducing additional nausea in participants by the incorporation of sensory exposure to foods ('cybersickness'). Nausea might in particular affect appetitive responding.
In sum, the present study adds to the existing literature that contextual appetitive conditioning induces conditioned responding (i.e., an increased desire for food and an increased liking of the CS) in healthy women, and it provides some evidence for the involvement of preparatory responses of the body (i.e., a conditioned salivary response). This study also uniquely associates impulsivity with increased food consumption in specifically a conditioned food-associated context. Future research should elucidate the complex role of impulsivity in the acquisition and expression of appetitive conditioning and ask the question why impulsivity is related to increased vulnerability to conditioned context-induced overeating. Also, research is needed on the implications for cue/ context exposure therapy, and how AR and VR can be used to develop optimal exposure therapy for appetitive disorders and substance use disorders.

\section{Funding}

This study is part of an ongoing project that is financed by the Netherlands Organisation for Scientific Research (NWO): Vici Grant 453.10.006, awarded to Anita Jansen. The Virtual Reality laboratory is financed by NWO: Middelgroot Grant 480.09.006.

\section{References}

Birch, L. L., McPhee, L., Sullivan, S., \& Johnson, S. (1989). Conditioned meal initiation in young children. Appetite, 13, 105-113.

Boggiano, M. M., Dorsey, J. R., Thomas, J. M., \& Murdaugh, D. L. (2009). The Pavlovian power of palatable food. Lessons for weight-loss adherence from a new rodent model of cue-induced overeating. International Journal of Obesity, 33, 693-701.

Botella, C. M., Juan, M. C., Baños, R. M., Alcañniz, M., Guillén, V., \& Rey, B. (2005). Mixing realities? An application of Augmented Reality for the treatment of cockroach Phobia. CyberPsychology \& Behavior, 8, 162-171.

Bouton, M. E. (2002). Context, ambiguity, and unlearning. Sources of relapse after behavioral extinction. Biological Psychiatry, 52, 976-986.

Burton, P., Smit, H. J., \& Lightowler, H. (2007). The influence of restrained and external eating patterns on overeating. Appetite, 49, 191-197.

Corr, P. J. (2001). Testing problems in J. A. Gray's personality theory. A commentary on. Personality and Individual Differences, 30, 333-352.

Corr, P. J., Pickering, A. D., \& Gray, J. A. (1995). Personality and reinforcement in associative and instrumental learning. Personality and Individual Differences, 19, 47-71.

Dawe, S., Gullo, M. J., \& Loxton, N. J. (2004). Reward drive and rash impulsiveness as dimensions of impulsivity. Implications for substance misuse. Addictive Behaviors, 29, 1389-1405.

De Zwaan, M., Mitchell, J. E., Seim, H. C., Specker, S. M., Pyle, R. L., Raymond, N. C., et al. (1994). Eating related and general psychopathology in obese females with binge eating disorder. International Journal of Eating Disorders, 15, 43-52.

Drummond, D. C. (2001). Theories of drug craving, ancient and modern. [Article]. Addiction, 96, 33-46.

Flegal, K. M., Carroll, M. D., Ogden, C. L., \& Curtin, L. R. (2010). Prevalence and trends in obesity among US adults, 1999-2008. JAMA. The Journal of the American Medical Association, 303, 235-241.

Guerrieri, R., Nederkoorn, C., \& Jansen, A (2008). The effect of an impulsive personality on overeating and obesity. Current state of affairs: University of Rijeka.

Gupta, S., \& Shukla, A. P. (1989). Verbal operant conditioning as a function of extraversion and reinforcement. British Journal of Psychology, 80, 39-44.

Havermans, R. C., \& Jansen, A. T. M. (2003). Increasing the efficacy of cue exposure treatment in preventing relapse of addictive behavior. Addictive Behaviors, 28, 989-994.

Hays, N. P., \& Roberts, S. B. (2007). Aspects of eating behaviors disinhibition and restraint are related to weight gain and BMI in women. Obesity, 16, 52-58.

Hoffman, H. G., Hollander, A., Schroder, K., Rousseau, S., \& Furness, T. (1998). Physically touching and tasting virtual objects enhances the realism of virtual experiences. Virtual Reality, 3, 226-234.

Hoffman, H. G., Richards, G., Coda, T., Richards, A., \& Sharar, S. R. (2003). The illusion of presence in immersive virtual reality during an fMRI brain scan. CyberPsychology \& Behavior, 6, 127-131.

Hogarth, L., Dickinson, A., Hutton, S. B., Bamborough, H., \& Duka, T. (2006). Contingency knowledge is necessary for learned motivated behaviour in humans. Relevance for addictive behaviour. Addiction, 101, 1153-1166.

Hou, R., Mogg, K., Bradley, B. P., Moss-Morris, R., Peveler, R., \& Roefs, A. (2011). External eating, impulsivity and attentional bias to food cues. Appetite, 56, 424-427.

Huskisson, E. C. (1974). Measurement of pain. The Lancet, 304, 1127-1131.

Jansen, A. (1998). A learning model of binge eating. Cue reactivity and cue exposure. Behaviour Research and Therapy, 36, 257-272. 
Jansen, A., Havermans, R., \& Nederkoorn, C. (2011). Cued overeating. In V. R. Preedy, R. R. Watson, \& C. R. Martin (Eds.), Handbook of behaviour, food and nutrition. New York: Springer.

Jansen, A., Klaver, J., Merckelbach, H., \& van den Hout, M. (1989). Restrained eaters are rapidly habituating sensation seekers. Behaviour Research and Therapy, 27, 247-252.

Jansen, A., Stegerman, S., Roefs, A., Nederkoorn, C., \& Havermans, R. (2010). Decreased salivation to food cues in formerly obese successful dieters. Psychotherapy and Psychosomatics, 79, 257-258.

Lovibond, P. F., \& Shanks, D. R. (2002). The role of awareness in Pavlovian conditioning. Empirical evidence and theoretical implications. Journal of Experimental Psychology. Animal Behavior Processes, 28, 3-26.

Mitterschiffthaler, M. T., Fu, C. H. Y., Dalton, J. A., Andrew, C. M., \& Williams, S. C. R. (2007). A functional MRI study of happy and sad affective states induced by classical music. Human Brain Mapping, 28, 1150-1162.

Nasser, J. A., Gluck, M. E., \& Geliebter, A. (2004). Impulsivity and test meal intake in obese binge eating women. Appetite, 43, 303-307.

Nederkoorn, C., Braet, C., Van Eijs, Y., Tanghe, A., \& Jansen, A. (2006). Why obese children cannot resist food. The role of impulsivity. Eating Behaviors, 7, $315-322$.

Nederkoorn, C., Guerrieri, R., Havermans, R. C., Roefs, A., \& Jansen, A. (2009). The interactive effect of hunger and impulsivity on food intake and purchase in a virtual supermarket. International Journal of Obesity, 33, 905-912.

Nederkoorn, C., Jansen, E., Mulkens, S., \& Jansen, A. (2007). Impulsivity predicts treatment outcome in obese children. Behaviour Research and Therapy, 45, 1071-1075.

Nederkoorn, C., Smulders, F. T. Y., Havermans, R. C., Roefs, A., \& Jansen, A. (2006). Impulsivity in obese women. Appetite, 47, 253-256.

Nederkoorn, C., Smulders, F. T. Y., \& Jansen, A. (2000). Cephalic phase responses, craving and food intake in normal subjects. Appetite, 35, 45-55.

Paisey, T. J. H., \& Mangan, G. L. (1988). Personality and conditioning with appetitive and aversive stimuli. Personality and Individual Differences, 9, 69-78.

Papachristou, H., Nederkoorn, C., Beunen, S., \& Jansen, A. (2013). Dissection of appetitive conditioning. Does impulsivity play a role? Appetite, 69, 46-53.

Patton, J. H., Stanford, M. S., \& Barratt, E. S. (1995). Factor structure of the barratt impulsiveness scale. Journal of Clinical Psychology, 51, 768-774.

Petrovich, G. D., Ross, C. A., Gallagher, M., \& Holland, P. C. (2007). Learned contextual cue potentiates eating in rats. Physiology E Behavior, 90, 362-367.

Polivy, J., Herman, C. P., \& Howard, K. (1988). The Restraint Scale. Assessment of dieting. In M. Hersen \& S. Bellack (Eds.), Dictionary of behavioural assessment techniques (pp. 377-380). New York: Pergamon.
Powley, T. L. (1977). The ventromedial hypothalamic syndrome, satiety, and a cephalic phase hypothesis. Psychological Review, 84, 89-126.

Rodin, J., \& Slochower, J. (1976). Externality in the nonobese. Effects of environmental responsiveness on weight. Journal of Personality and Social Psychology, 33, 338-344.

Rydén, A., Sullivan, M., Torgerson, J. S., Karlsson, J., Lindroos, A. K., \& Taft, C. (2003). Severe obesity and personality. A comparative controlled study of personality traits. International Journal of Obesity and Related Metabolic Disorders, 27. 1534-1540.

Sturm, R. (2002). The effects of obesity, smoking, and drinking on medical problems and costs. Health Affairs, 21, 2245-2253.

Swinburn, B., Egger, G., \& Raza, F. (1999). Dissecting obesogenic environments. The development and application of a framework for identifying and prioritizing environmental interventions for obesity. Preventive Medicine, 29, 563-570.

Tetley, A. C., Brunstrom, J. M., \& Griffiths, P. L. (2010). The role of sensitivity to reward and impulsivity in food-cue reactivity. Eating Behaviors, 11, 138-143.

Thewissen, R., Van Den Hout, M., Havermans, R. C., \& Jansen, A. (2005). Contextdependency of cue-elicited urge to smoke. Addiction, 100, 387-396.

Van Gucht, D., Baeyens, F., Hermans, D., \& Beckers, T. (2013). The inertia of conditioned craving. Does context modulate the effect of counterconditioning? Appetite, 65, 51-57.

Van Gucht, D., Baeyens, F., Vansteenwegen, D., Hermans, D., \& Beckers, T. (2010) Counterconditioning reduces cue-induced craving and actual cue-elicited consumption. Emotion, 10, 688-695.

Van Gucht, D., Vansteenwegen, D., Beckers, T., \& Van den Bergh, O. (2008). Return of experimentally induced chocolate craving after extinction in a different context. Divergence between craving for and expecting to eat chocolate. Behaviour Research and Therapy, 46, 375-391.

Van Gucht, D., Vansteenwegen, D., Van den Bergh, O., \& Beckers, T. (2008). Conditioned craving cues elicit an automatic approach tendency. Behaviour Research and Therapy, 46, 1160-1169.

Wardle, J. (1990). Conditioning processes and cue exposure in the modification of excessive eating. Addictive Behaviors, 15, 387-393.

Witmer, B. G., \& Singer, M. J. (1998). Measuring presence in virtual environments. A presence questionnaire. Presence. Teleoperators and Virtual Environments, 7, $225-240$.

Zinbarg, R. E., \& Mohlman, J. (1998). Individual differences in the acquisition of affectively valenced associations. Journal of Personality and Social Psychology, 74, 1024-1040.

Zinbarg, R. E., \& Revelle, W. (1989). Personality and conditioning. A test of four models. Journal of Personality and Social Psychology, 57, 301-314. 